\title{
Poor management of menstrual hygiene: a leading cause of school absenteeism among adolescent girls in the urban slum of Madhya Pradesh
}

\author{
Surya Bali', Sembagamuthu Sembiah ${ }^{1 *}$, Kriti $\operatorname{Yadav}^{1}$, Jayeeta Burman²
}

\author{
${ }^{1}$ Department of Community and Family Medicine, All India Institute of Medical Sciences (AIIMS) Bhopal, Madhya \\ Pradesh, India \\ ${ }^{2}$ Department of Community Medicine, NRS Medical College, Kolkata, West Bengal, India
}

Received: 19 July 2020

Revised: 04 September 2020

Accepted: 05 September 2020

\section{*Correspondence:}

Dr. Sembagamuthu Sembiah,

E-mail: semba9.ss@gmail.com

Copyright: (C) the author(s), publisher and licensee Medip Academy. This is an open-access article distributed under the terms of the Creative Commons Attribution Non-Commercial License, which permits unrestricted non-commercial use, distribution, and reproduction in any medium, provided the original work is properly cited.

\begin{abstract}
Background: Despite the strides made in the field of adolescent and women health, menstrual problems remain a stigma. Unsatisfactory menstrual hygiene practices have a profound influence on the adolescent girl's health and academic performance. Therefore, the present study aimed to assess the relationship between school absenteeism and poor MHM and its impacts on school girl's day to day lives.

Methods: This is a cross-sectional study conducted among 384 adolescent girls enrolled in anganwadi centres of the urban slum of Madhya Pradesh from January to June 2018. A pre-designed and pretested questionnaire used to collect the data regarding menstrual hygiene practices and school absenteeism. Data were analyzed using the SPSS software (version 16.0. Chicago, SPSS Inc.).

Results: The study found that around two-thirds $(64.3 \%)$ and nearly one third (30\%) of the participants were using a simple cloth and sanitary pads. About half $(50.6 \%)$ of the respondents miss their school during the menstruation. Majority of them perceived that menstruation interferes with their school performance. The main reason for missing the schools was fear/ shame of leakage. In multivariable regression lack of sanitary facilities and painful menstruation remained significant predictors of school absenteeism.

Conclusions: There is a dire need to fortify efforts directed towards increasing awareness on menstrual hygiene, to revamp the existing measures for improving menstrual health of the adolescent girls. Focused attention is warranted by policymakers to improve the quality of life of this vulnerable group.
\end{abstract}

Keywords: Adolescent girls, Menstrual hygiene, School absenteeism

\section{INTRODUCTION}

Adolescent girls constitute a vulnerable group, particularly in India female child is a neglected one. Menstruation is a normal biological process in the lives of every female still it's been covered in mystery and taboo, not to speak about openly cause of the society's lack of knowledge, misconceptions and malpractices. ${ }^{1}$ Lack of knowledge and poor menstrual hygiene management (MHM) makes them prone to STI/RTIs, severe lower abdominal pains and cramps and stress affects their quality of life in the long term. ${ }^{1}$ Not only that most of the girls were anxious just over thought on their menstrual period itself and afraid of getting stained in clothes throughout the period.

Lack of access to clean, effective absorbents; inadequate facilities to change, clean and dispose of absorbents; lack of access to soap and water; and lack of privacy will hamper the effective menstrual hygiene management 
(MHM). ${ }^{2-4}$ Besides, inadequate social support and presence of taboos can lead to psychosocial consequences of menstruation including shame, fear, anxiety and distraction. ${ }^{2-4}$ These can potentially affect girls' ability to thrive and succeed within the school environment. ${ }^{5}$ In India, 23 million girls drop out of school early when they start menstruating, many of them end up facing acute health problems. ${ }^{6}$

Addressing MHM contributes to millennium development goal-5 (MDG) directly improving maternal health. Due to its indirect effect on school absenteeism and gender discrepancy, poor menstrual hygiene and management may seriously hamper the realization of MDG-2 on universal education and MDG-3 on gender equality and women empowerment. ${ }^{7}$ Young girls are considered healthy their health concerns are not well taken generally and face lots of gender discrimination. Urban slum adolescents were more neglected in terms of healthcare services as they not enrolled in any of the administrative sections.

The government charted various initiatives to deal with this public health issue like menstrual hygiene promotion as one of the responsibilities of the Accredited Social Health Activist (2005) followed by menstrual hygiene promotion scheme for girls in rural areas in 2011. In 2015, the Ministry of Drinking Water and Sanitation drafted the guidelines on MHM. Menstrual hygiene usually thought to be a multi-sectoral issue that needs an integrated action from various departments such as education, health, women, and child development and water sanitation hygiene (WASH).

\section{Objective of the study}

The present study carried out to assess the current status of menstrual hygiene management (MHM) in schools in urban slums of Bhopal. The study tried to establish the relationship between school absenteeism and poor MHM, reveal its impacts on school girl's day to day lives and the difficulties the girls experience in managing menstrual hygiene. It will help health policy makers to develop appropriate intervention to overcome these issues.

\section{METHODS}

This was a community-based cross-sectional study conducted among menstruating Adolescent girls (10-19 years) enrolled in Anganwadi centres in Banganga, an urban slum of Bhopal District, MP from January to June 2018. As this study is first of its kind in this study area, the prevalence of school absenteeism due to menstruation was assumed to be $50 \%$.

Considering the margin of error to be $10 \%$ using formula $\mathrm{z}^{2} \mathrm{pq} / \mathrm{d}^{2}(\mathrm{z}=$ standard normal deviate at $95 \%$ confidence interval $[\mathrm{CI}]$; $\mathrm{q}=100-\mathrm{p})$, the estimated minimum sample size was 384 . Line listing of the adolescents prepared and simple random sampling used to select the participants.
A pre-designed, pretested and structured questionnaire used to collect the data through face to face interview of the study participants.

\section{Outcome variable}

School absenteeism of students during menstruation which enquires about the average number of days absent; reasons for not attending the school; whether menstruation interferes with their school performance

\section{Independent variables}

These include socio-demographic characteristics; knowledge and source of information about menstruation; menstruation characteristics (age at menarche; pain and flow characteristics, health issues related to menstruation, activities restricted at home); menstrual hygiene management practices (use, storage, disposal, frequency of change of absorbent; washing of external genitalia); and school environment for menstrual hygiene management (toilet facilities; a place for changing and dispose of used pads; any discrimination faced by the girls).

Ethical clearance from the Institutional Human Ethics Committee (IHEC) of AIIMS Bhopal, Madhya Pradesh was obtained. Each study participant was informed about the purpose, benefits, risks and their right to discontinue or refuses to participate in the study. Every participant had given written informed consent and assent obtained for respondents whose age less than 18 years of age from their parents/guardians assured that their confidentiality, privacy and anonymity be maintained.

\section{Statistical analysis}

Data were analyzed using the statistical package of social science software version 16.0 (IBM, SPSS Inc., Chicago, USA). Descriptive statistics calculated. Univariate and multivariable logistic regression was performed with $95 \%$ confidence level $(\mathrm{p}<0.05)$ to identify the factors associated with school absenteeism.

\section{RESULTS}

The mean age (SD) of study participants was 15.57 (1.8) with $62.4 \%$ of the respondents in the age group of 15 to18. About three fourth of the participants were pursuing intermediate (9-12 classes) schooling. Around half and one fourth, the participants belonged to other backward and scheduled castes. About $81.4 \%$ of the respondents belonged to below poverty line category. About $27 \%$ of the mothers of the participants were illiterate (Table 1).

About $49 \%$ of the participants attained menarche at the age of 13 years. Around $60 \%$ of the participants were not aware of menstruation before menarche. Nearly onefourth $(23.2 \%)$ of the participants know the exact cause of menstruation. Even $3 \%$ of the respondents claimed that 
it is a curse of God. Only $4 \%$ of the participants correctly mentioned the organ from where the menstrual flow occurs. Around four-fifth (83\%) and $75 \%$ of the participants suffered from some or other health issues and claimed that the daily activities restricted at home. Around two-thirds (64.3\%) of the participants were using simple cloth; only $30 \%$ of them were using sanitary pads; $12.4 \%$ of them didn't store the absorbent. About $40 \%$ of the participants throw it in the gutter nearby. About three fourth of the respondents clean their external genitalia more than two times a day (Tables 2 and 3).

Table 1: Socio demographic characteristics of the study participants $(n=393)$.

\begin{tabular}{|ll|}
\hline Characteristics & No. $(\%)$ \\
\hline Age & $125(31.8)$ \\
\hline $11-14$ & $245(62.4)$ \\
\hline $15-18$ & $23(5.8)$ \\
\hline$>18$ & $15.57(1.8) ; 16 ; 11$ \\
to 20.
\end{tabular}

About half $(50.6 \%)$ of the respondents miss their school during the menstruation. Around three fourth miss their school for about two to three days. The main reason for missing the schools was fear/shame of leakage. More than half $(60 \%)$ and $50 \%$ of the respondents claimed that lack of concentration in the classes and inability to participate in sports respectively. About $10 \%$ of the respondents perceived that academic performance has reduced due to menstruation (Table 4).

Table 2: Knowledge and characteristics of menstruation among the study participants $(n=393)$.

\begin{tabular}{|c|c|}
\hline Age at menarche & No $(\%)$ \\
\hline 11 years and less & $21(5.3)$ \\
\hline 12 years & $92(23.5)$ \\
\hline 13 years & $193(49.1)$ \\
\hline 14 years and more & $83(21.1)$ \\
\hline \multicolumn{2}{|c|}{ Awareness about menstruation before menarche } \\
\hline Yes & $154(39.2)$ \\
\hline No & $239(60.8)$ \\
\hline \multicolumn{2}{|c|}{ Source of information before menarche* } \\
\hline Mother & $136(32.1)$ \\
\hline Sister & $33(8.4)$ \\
\hline Friend & $37(9.4)$ \\
\hline Teacher & $57(14.5)$ \\
\hline Television/print materials & $11(2.8)$ \\
\hline \multicolumn{2}{|c|}{ Knowledge regarding menstruation } \\
\hline \multicolumn{2}{|c|}{ What is the cause of menstruation? } \\
\hline Physiological process & $91(23.2)$ \\
\hline Because of eating & $1(0.3)$ \\
\hline Clean body & $1(0.3)$ \\
\hline Curse of god & $13(3.3)$ \\
\hline Don't Know & $284(72.3)$ \\
\hline \multicolumn{2}{|c|}{ Organ from which the menstrual blood comes } \\
\hline Uterus & $17(4.3)$ \\
\hline Vagina & $25(6.4)$ \\
\hline Urethra & $89(22.6)$ \\
\hline Don't know & $262(66.7)$ \\
\hline \multicolumn{2}{|c|}{ Current status of menstrual cycle } \\
\hline Irregular & $95(24.2)$ \\
\hline Regular & $298(75.8)$ \\
\hline \multicolumn{2}{|l|}{ Pain } \\
\hline Painful & $256(65.1)$ \\
\hline Painless & $137(33.9)$ \\
\hline \multicolumn{2}{|l|}{ Bleeding } \\
\hline Normal & $144(36.6)$ \\
\hline Excessive & $194(49.3)$ \\
\hline Scanty & $55(13.9)$ \\
\hline \multicolumn{2}{|c|}{ Health issues due to menstruation } \\
\hline Yes & $326(83)$ \\
\hline No & $67(17)$ \\
\hline \multicolumn{2}{|c|}{ Activities Restricted during menstruation at home } \\
\hline Yes & $296(75.3)$ \\
\hline No & $97(24.7)$ \\
\hline
\end{tabular}

Table 3: Menstrual hygiene management of the study participants $(\mathbf{n}=393)$.

Absorbent used for recent menstruation

\begin{tabular}{ll} 
Sanitary napkins & $121(30.7)$ \\
\hline Simple cloth & $253(64.3)$ \\
\hline Cotton & $19(4.8)$ \\
\hline Storage of materials at home & \\
\hline Cupboard & $251(63.9)$ \\
\hline
\end{tabular}

Continued. 


\begin{tabular}{|ll|}
\hline Absorbent used for recent menstruation & \\
\hline Bathroom & $58(14.8)$ \\
\hline Other hidden places & $35(8.9)$ \\
\hline Don't store & $49(12.4)$ \\
\hline Method of disposal & $169(43)$ \\
\hline Throw it in routine waste & $161(40.9)$ \\
\hline Throw it in the gutter nearby & $37(9.4)$ \\
\hline Buried & $14(3.6)$ \\
\hline Burn & $12(3.1)$ \\
\hline Flush it in the latrine & $239(60.8)$ \\
\hline Average number of absorbent used per day \\
\hline$\leq 2$ & $154(39.2)$ \\
\hline$>2$ & $262(66.7)$ \\
\hline Cleaning of external genitalia & $131(33.3)$ \\
\hline Satisfactory (>2 times a day) & $283(72)$ \\
\hline Unsatisfactory ( $\leq 2$ times a day) & $100(25.4)$ \\
\hline Genital cleaning material & $10(2.6)$ \\
\hline Only water & \\
\hline Soap and water & \\
\hline Water and antiseptic &
\end{tabular}

Table 4: School absenteeism related to menstruation $(n=393)$.

\begin{tabular}{|ll|}
\hline \multicolumn{2}{|l|}{ School absent during menstruation in past year } \\
\hline Yes & $196(50.6)$ \\
\hline No & $194(49.4)$ \\
\hline Number of days absent per month (n=196) \\
\hline 1 & $55(28.1)$ \\
\hline $2-3$ & $127(64.8)$ \\
\hline$>3$ & $14(7.1)$ \\
\hline Reasons for absenteeism* & $294(74.8)$ \\
\hline Shame / fear of leakage & $157(39.9)$ \\
\hline Pain or discomfort & $107(27.2)$ \\
\hline Excessive bleeding & $113(28.7)$ \\
\hline No private place (toilet) to change the & \\
sanitary pad & $97(24.7)$ \\
\hline Inadequate water in the school & $136(32.1)$ \\
\hline No place to dispose used pad & $20(5.1)$ \\
\hline Family restrictions & $63(16)$ \\
\hline Faced discrimination in schools & $296(75.4)$ \\
\hline Effect of menstruation on school performance* & \\
\hline Menstruation interferes school performance & $236(60)$ \\
\hline Lack of concentration & $51(12.9)$ \\
\hline Unable to answer questions in class & $21(5.35)$ \\
\hline Miss class test/examination & $34(8.6)$ \\
\hline Avoid sitting in a group & $198(50.4)$ \\
\hline Inability to participate in sports & $37(9.4)$ \\
\hline Poor academic performance & $97(24.6)$ \\
\hline No interference & \\
\hline *multiple response & \\
\hline
\end{tabular}

Univariate logistic regression showed the educational status of the girl, painful menstruation, lack of sanitary facilities such as toilet facilities, changing pads and disposal of used pads were significant determinants of school absenteeism. Whereas in multivariable regression lack of sanitation facilities and painful menstruation remained significant predictors of school absenteeism (Table 5).

Table 5: Regression analysis showing factors associated with school absenteeism.

\begin{tabular}{|c|c|c|}
\hline Variable & Crude OR & Adjusted OR \\
\hline Age (>15 years) & $1.1(0.7-1.7)$ & \\
\hline $\begin{array}{l}\text { Education (below } 9^{\text {th }} \\
\text { standard) }\end{array}$ & $2.1(1.2-3.5)^{* *}$ & $\begin{array}{l}1.2 \\
(0.6-2.2)\end{array}$ \\
\hline Religion (Muslim) & $1(0.6-1.6)$ & \\
\hline Caste (OBC) & $0.6(0.4-1.1)$ & \\
\hline Caste (SC/ST) & $0.4(0.2-1.2)$ & \\
\hline SES (BPL) & $1.2(0.7-2)$ & \\
\hline $\begin{array}{l}\text { Mother's education (upto } \\
\text { primary) }\end{array}$ & $1.3(0.1-2)$ & \\
\hline $\begin{array}{l}\text { Father's education (upto } \\
\text { primary) }\end{array}$ & $1.2(0.8-1.8)$ & \\
\hline Age at menarche (>12) & $1.3(0.8-2)$ & \\
\hline $\begin{array}{l}\text { Awareness before } \\
\text { menarche (yes) }\end{array}$ & $1.1(0.7-1.7)$ & \\
\hline Knowledge (poor) & $1.2(0.7-2)$ & \\
\hline $\begin{array}{l}\text { Menstrual cycle } \\
\text { (irregular) }\end{array}$ & $1.2(0.7-1.9)$ & \\
\hline $\begin{array}{l}\text { Absorbent (sanitary } \\
\text { napkin) }\end{array}$ & $1.1(0.6-1.7)$ & \\
\hline $\begin{array}{l}\text { Cleaning of external } \\
\text { genitalia }\end{array}$ & $1.1(0.7-1.6)$ & \\
\hline $\begin{array}{l}\text { Storage of materials at } \\
\text { home }\end{array}$ & $1.1(0.5-2.2)$ & \\
\hline Painful & $\begin{array}{l}2.9 \\
(1.8-4.6)^{* * * *}\end{array}$ & $\begin{array}{l}2.4 \\
(1.5-4.1) * * *\end{array}$ \\
\hline $\begin{array}{l}\text { Lack of facilities at school } \\
\text { (yes) }\end{array}$ & $9(5.7-17)^{* * *}$ & $\begin{array}{l}3.1 \\
(1.4-7) * * *\end{array}$ \\
\hline $\begin{array}{l}\text { School discrimination } \\
\text { (Yes) }\end{array}$ & $1.4(0.8-2.5)$ & \\
\hline Health issue (yes) & $1.2(0.7-2)$ & \\
\hline Restriction at home (yes) & $1.4(0.9-2.3)$ & \\
\hline
\end{tabular}

\section{DISCUSSION}

Girls are on par with boys up to adolescence, with the onset of puberty, girls face increasing restrictions to their activities and mobility impacting women and girls' education, health, and workforce participation which deviates the outcomes for girls. ${ }^{8}$ Across the country, millions of women still face significant barriers to a comfortable and dignified experience with menstrual hygiene management (MHM). Menstrual health promotion remains an issue of concern in India. To date, most studies have focused on knowledge, attitude and practice of MHM among urban and rural primary school students, and this study adds to the literature in focusing on slum population. Very few studies focus on school absenteeism as an outcome. So this study tries to explore the limitation of adolescents on attending schools and how it affects their academic performance. 
In the present study, age at menarche of adolescent schoolgirls ranged between 10 and 16 years with most of the girls attained at the age of 13 years similar to other studies done at Delhi, Chandigarh and Nagpur. ${ }^{9-11}$ The present study found that $60 \%$ were unaware of menstruation before menarche consistent with the findings of other studies and even higher (70\%) in a study in rural Varanasi. ${ }^{9-13}$ The present study found that mothers followed by teachers were significant sources of information before menarche, which is similar to another study in the urban area of Bhopal where $70 \%$ of girls made aware by the mothers. ${ }^{12}$ Whereas studies in Delhi and Ethiopia found teachers as the first informants for $85 \%$ and $50.4 \%$ of the girls, respectively. ${ }^{9,14}$ A study in rural Varanasi reported sisters $(55 \%)$ played a significant role in providing information to them. ${ }^{13}$

In the present study, around one third $(30.7 \%)$ of the respondents were using sanitary pads, a study in rural Varanasi and Ghaziabad showed similar results. ${ }^{13,15}$ Another study in Bhopal showed only $22 \%$ used sanitary napkins; $62 \%$ used simple cloth as absorbents. ${ }^{12}$ A study in Nagpur showed nearly half $(48.3 \%)$ of the girls used sanitary pads which is higher than the current study; the difference is due to urban and slum difference. ${ }^{11}$

\section{Prevalence of school absenteeism related to menstruation}

In the present study around half (50.6\%) of the participants had been absent from school during their menstrual period in last one year which is higher than studies in Delhi (40\%), rural Pune (43.2\%), West Bengal (39\%), Bangladesh (41\%). As all these studies conducted in economically stable areas where sanitary facilities and awareness about menstruation were available. ${ }^{9,16-18}$ The studies in Ghaziabad (64\%) and Ethiopia (54.5\%) showed a higher prevalence than the present study cause of the study area difference. ${ }^{14,15}$ Another survey in three states of India showed less proportion of absenteeism than the present study: Maharashtra (10.1\%), Chhattisgarh (20.7), Tamil Nadu (3.5\%), as the survey included urban and rural students who are economically sound. ${ }^{19}$ Whereas another study among nursing students in Tamil Nadu found that $67 \%$ of respondents not interested in going to the college during menstruation. ${ }^{20}$ In the present study, $64 \%$ were absent for two to three days during menstruation similar to a study in Bangladesh; a study in Uganda reported $19.7 \%$ missing at least one day of school, during their most recent period. The main reason for more number of days absent is due to stigma and inadequate facilities in the school. ${ }^{18,21}$ A study in Delhi found that the mean number of absent days was 1.2 \pm 0.7 , way less than the present study as the study done on slum girls. ${ }^{9}$

\section{Reasons for absenteeism}

The present study showed Pain $(\mathrm{OR}=2.4)$ as the main predictor of school absenteeism during menstruation similar to studies done in Uganda $(\mathrm{OR}=1.9)$, rural Pune $(\mathrm{OR}=13) .{ }^{16,21}$ Besides, the present study found that the girls who experienced teasing and humiliation by classmates were prone to school absenteeism which is not significant in the present study and similar results found in Ghaziabad. ${ }^{15}$ The present study showed no significant association between socioeconomic status and education of parents; a study in rural Pune showed socioeconomic status as a predictor of school absenteeism. ${ }^{16}$ A survey in three states of India found that the only variables related to sanitary facilities at school, "clean toilets", "toilet breaks", and "can wash in school" remained significant similar to the present study. The survey found that around $46 \%$ of girls saying there were not enough toilets, and only $37 \%$ saying they were for girls only whereas government systems suggest that all schools should have enough gender-specific toilets. ${ }^{19}$ Even if the toilet is present, they were unusable the girls preferred to go outside or stay home.

Lack of knowledge about menstruation before menarche makes the girls perceive it as something unhealthy, shameful or obstructive to learning. Girl's attitude, misconceptions about menstruation and family restriction were other main risk factors for school absence which is inconsistent with the present study. ${ }^{20,28-30}$ Multiple intervention trials concluded that improved facilities for menstrual hygiene and delivering comprehensive sexual and reproductive health education programmes that address knowledge and practical skills relating to menstruation and MHM, including pain management have measurably improved girls' attendance. ${ }^{24,31,32}$

\section{Academic performance}

In our study, $75 \%$ of girls perceived that menstruation interferes with school performance and activities at school shows that the menstruation not only has an impact on absenteeism but also affected the quality of school time. The fear of shame made difficult for the girls to stay in class and it also restricts the girls from outdoor activities similar to studies in Delhi where 69\% girls reported that menstruation did affect their school life. ${ }^{9}$ About $60 \%$ of participants in the present study reported about lack of concentration during study hours similar to a survey in three states (50\%); a study in Tamil Nadu showed higher proportion $(71 \%)$ reported about lack of concentration. $^{20}$ These problems were affected by the type of menstrual item used, as more common among users of cloth compared to disposable pad users. ${ }^{18} \mathrm{~A}$ study in Iraq schools found a higher percentage of students $(62 \%)$ revealed that menstruation affected either their grades or they missed the examinations, in $57 \%$, it interferes their participation in-class activities and presentations; the present study reported around $10 \%$ reported poor academic performance. ${ }^{32}$

This study allows understanding menstrual management in-depth with a large sample size, especially in most neglected population. Assessing school attendance 
through quantitative surveys includes possible underreporting as they don't want to report school absenteeism, or to name menstruation as a reason for this. Sometimes girls also may leave school early and miss hours of a school day due to menstruation, which would not be counted as an absence. Qualitative studies will give a clearer picture of various level factors and the complications related to MHM and practical solutions for this issue.

\section{CONCLUSION}

The present study found that about half $(50.6 \%)$ of the adolescent girls were being absent in schools during the menstruation. Around $75 \%$ perceived that the menstruation interferes on school performance. The main reason for the same is painful menstruation and lack of sanitary facilities at school. It implies the fact that if the facilities for menstrual hygiene management at school are available, it can reduce the school absenteeism. For which, there is a need to strengthen the mechanisms to spread awareness on menstrual hygiene not only to the girls and their parents and the whole society to break the myths and taboos surrounding menstruation so that the schemes and initiatives reach the ground level. Simultaneously, provisions of sanitary napkins at subsidy and strengthening sanitation facilities for school students through various schemes such as Menstrual Hygiene Scheme and Swacch Bharat Abhiyan should be made available for the betterment of millions of women.

Funding: No funding sources

Conflict of interest: None declared

Ethical approval: The study was approved by the Institutional Ethics Committee AIIMS Bhopal, Madhya Pradesh

\section{REFERENCES}

1. Bobhate PS, Shrivastava SR. A cross sectional study of knowledge and practices about reproductive health among female adolescents in an urban slum of Mumbai. J Fam Reprod Health. 2011;5(4):119-26.

2. Mason L, Nyothach E, Alexander K, Odhiambo FO, Eleveld A, Vulule J, et al. 'We keep it secret so no one should know'- a qualitative study to explore young schoolgirls attitudes and experiences with menstruation in rural western Kenya. PLoS One. 2013;8(11):e79132.

3. Phillips-Howard PA, Caruso BA, Torondel B, Zulaika G, Sahin M, Sommer M. Menstrual hygiene management among adolescent schoolgirls in lowand middle-income countries: research priorities. Glob Health Action. 2016;9:33032.

4. McMahon SA, Winch PJ, Caruso BA, Obure AF, Ogutu EA, Ochari IA, Rheingans RD. 'The girl with her period is the one to hang her head' reflections on menstrual management among schoolgirls in rural Kenya. BMC Int Health Hum Rights. 2011;11:7.
5. Sommer M. Where the education system and women's bodies collide: the social and health impact of girls' experiences of menstruation and schooling in Tanzania. J Adolesc. 2010; 33(4):521-9.

6. SSindu T. Psychosocial impact related to physiological changes preceding, at and following menarche among adolescent girls. Int J Clin Surg Adv. 2014;2(1):42-53.

7. Vashisht A, Pathak R, Agarwalla R, Patavegar BN, Panda M. School absenteeism during menstruation amongst adolescent girls in Delhi, India. J Fam Community Med. 2018;25:163-8.

8. Kumar D, Goel NK, Puri S, Pathak R, Sarpal SS, Gupta S, et al. Menstrual pattern among unmarried women from Northern India. J Clin Diagn Res. 2013;7:1926-9.

9. Thakre SB, Thakre SS, Reddy M, Rathi N, Pathak K, Ughade S. Menstrual hygiene: Knowledge and practice among adolescent school girls of Saoner, Nagpur district. J Clin Diagn Res. 2011;5:1027-33.

10. Sultan S, Sahu DS. Knowledge, attitude and practices about menstruation and related problems in adolescent girls. Int J Reprod Contracept Obstet Gynecol. 2017;6:5235-40.

11. Kansal S, Singh S, Kumar A. Menstrual hygiene practices in context of schooling: a community study among rural adolescent girls in Varanasi. Indian $\mathbf{J}$ Community Med. 2016;41(1):39.

12. Upashe SP, Tekelab T, Mekonnen J. Assessment of knowledge and practice of menstrual hygiene among high school girls in Western Ethiopia. BMC Womens Health. 2015;15:84.

13. Gupta M, Agarwal N, Agarwal A. Knowledge and practices related to menstruation and their relation to school absenteeism among adolescent girls attending tertiary care hospital in Ghaziabad: A cross sectional study. Panacea J Med Sci. 2019;9(2):43-7.

14. Bodat S, Ghate MM, Majumdar JR. School absenteeism during menstruation among rural adolescent girls in Pune. Nat J Community Med. 2013;4(2):212-6.

15. Sudeshna R, Aparajita D. Determinants of menstrual hygiene among adolescent girls: a multivariate analysis. Nat J Community Med. 2012;3(2):294-301.

16. Alam MU, Luby SP, Halder AK, Islam K, Opel A, Shoab AK, et al. Menstrual hygiene management among Bangladeshi adolescent schoolgirls and risk factors affecting school absence: results from a cross-sectional survey. BMJ Open. 2017;7(7):e015508.

17. Sivakami M, van Eijk AM, Thakur H, Kakade N, Patil C, Shinde S, et al. Effect of menstruation on girls and their schooling, and facilitators of menstrual hygiene management in schools: surveys in government schools in three states in India, 2015. J Glob Health. 2019;9(1).

18. Raju J, Suguna M. A study to assess the effect of menstrual symptoms on academic performance among nursing students at selected colleges in Tamil Nadu, India. IJAR. 2017;3(3):78-80. 
19. Miiro G, Rutakumwa R, Nakiyingi-Miiro J, Nakuya K. Menstrual health and school absenteeism among adolescent girls in Uganda (MENISCUS): a feasibility study. BMC Women's Health. 2018;18:4.

20. Tegegne TK, Sisay MM. Menstrual hygiene management and school absenteeism among female adolescent students in Northeast Ethiopia. BMC Public Health. 2014:14:1118.

21. Grant M, Lloyd C, Mensch B. Menstruation and school absenteeism: evidence from rural Malawi. Comp Educ Rev. 2013:57:260-84.

22. Davis J, Macintyre A, Odagiri M, Suriastini W, Cordova A, Huggett $\mathrm{C}$, et al. Menstrual hygiene management and school absenteeism among adolescent students in Indonesia: evidence from a cross-sectional school-based survey. Trop Med Int Health. 2018;23(12).

23. Lawan UM, Yusuf NW, Musa AB. Menstruation and menstrual hygiene amongst adolescent school girls in Kano, Northwestern Nigeria. Afr J Reprod Health. 2010;14:201-7.

24. Kumar A, Taunk A. A study of sanitation of toilets in elementary and senior Secondary schools located in rural areas of Uttarakhand state in India. Int $\mathbf{J}$ Sociol Anthropol. 2010;2(8):178.

25. Majra JP, Gur A. School environment and sanitation in rural India. J Glob Infect Dis. 2010;2(2):109-11.

26. Joshi D, Buit G, González-Botero D. Menstrual hygiene management: education and empowerment for girls? Waterlines. 2015;34:51-67.

27. Tamiru S, Mamo K, Acidria P, Mushi R, Ali CS, Ndebele L. Towards a sustainable solution for school menstrual hygiene management: cases of Ethiopia,
Uganda, South-Sudan, Tanzania, and Zimbabwe. Waterlines. 2015:92-102.

28. Trinies V, Caruso BA, Sogoré A, Toubkiss J, Freeman MC. Uncovering the challenges to menstrual hygiene management in schools in Mali. Waterlines. 2015;34:31-40.

29. Haque SE, Rahman M, Itsuko K, Mutahara M, Sakisaka K. The effect of a school-based educational intervention on menstrual health: an intervention study among adolescent girls in Bangladesh. BMJ Open. 2014;4:e004607.

30. Montgomery P, Ryus CR, Dolan CS, Dopson S, Scott LM. Sanitary pad interventionsbfor girls' education in Ghana: a pilot study. PLoS One. 2012;7:48274.

31. Freeman MC, Greene LE, Dreibelbis R, Saboori S, Muga R, Brumback B, et al. Assessing the impact of a school-based water treatment, hygiene and sanitation programme on pupil absence in Nyanza Province, Kenya: a cluster-randomized trial. Trop Med Int Health. 2012;17(3):380-91.

32. Ahmed HM, Piro SS. Impact of menstruation on school performance in Sarwaran and Shahid Khajabawa high school in Erbil city. Kufa J Nurs Sci. 2012;2:166-71.

Cite this article as: Bali S, Sembiah $\mathrm{S}$, Yadav K, Burman J. Poor management of menstrual hygiene: a leading cause of school absenteeism among adolescent girls in the urban slum of Madhya Pradesh. Int J Reprod Contracept Obstet Gynecol 2020;9:4102-8. 